\title{
How is cultural diversity positioned in teacher professional standards?: an international analysis.
}

\author{
Ninetta Santoro \\ Aileen Kennedy \\ University of Strathclyde \\ Scotland
}

\begin{abstract}
Unprecedented levels of global mobility mean that culturally homogenous classrooms are now increasingly rare. This brings with it challenges for teachers and raises issues about what constitutes quality teaching and teachers. Professional standards are commonly seen as a key policy instrument through which teacher quality can be enhanced. This article presents an analysis of teacher professional standards from five of the most culturally diverse nations in the English speaking world. Using critical discourse analysis we examine how culturally and linguistically diverse learners and culturally responsive pedagogy are positioned, and what the standards stipulate teachers should know, and be able to do, in fulfilling their professional obligations. We conclude by raising concerns about how the official representations of teaching in particular national contexts fail to position culturally diverse learners and culturally responsive teaching as a priority.
\end{abstract}

\section{Introduction}

In the last two decades in most parts of the world, the nature of teachers' work and the knowledge they require for increasingly complex teaching has undergone enormous change. In part, these changes have occurred in response to unprecedented levels of global mobility. Culturally homogenous classrooms are rare in most places in Europe and elsewhere, such as the USA, Canada and Australia (OECD, 2011). Of particular significance is the rapid rate of demographic change in some countries. For example, countries that were relatively homogenous such as Iceland, have seen a significant increase in immigration in the past 10 
years with $7.9 \%$ of the Icelandic population in 2012 being foreign born (OECD, 2013). In Ireland, foreign born citizens increased by 143\% from 2002 to 2011, with those from Poland being the largest group, followed by Lithuanians, Romanians, Indians, Latvians and Hungarians (Government of Ireland, 2012). Countries such as the USA, Canada and Australia, sometimes referred to as 'classical immigration countries' or 'traditional immigration countries' (Dustmann, Frattini \& Lanzara, 2011), have experienced increased cultural diversity in specific geographical areas and regions in response to government resettlement policies (Australian Department of Immigration and Border Protection, 2014a). Additionally, although not due to global trends in immigration, the cultural and linguistic diversity of countries such as Australia, New Zealand, Canada and the United States of America, includes the diverse cultures and languages of Aboriginal and First Nations populations.

In general, the cultural diversity that characterises so many classrooms has increased the complexity of teachers' work. All teachers, regardless of their location, need to be culturally responsive practitioners who must be able to work productively with culturally and linguistically diverse children. A culturally responsive teacher is one who holds high expectations of culturally diverse students, respects and understands their cultural values, knowledge, practices and histories, draws upon and builds on diverse students' 'funds of knowledge' (Gonzales, Moll \& Amanti, 2005). A culturally responsive teacher promotes social justice through naming and critiquing discourses of inequality within and beyond the classroom. She or he has what Epstein and Gist (2013) call "pedagogical dexterity" (p.19), that is the ability to be pedagogically reflexive and reflective, and to respond to students' learning needs through curricula, assessment and classroom practices that are relevant and meaningful.

The professional imperative to address the needs of CALD students raises questions about what knowledge teachers need and what constitutes quality teachers and teaching for such contexts. While debates about quality in general have dominated education discourse for decades, increasingly, global policy discourse promotes professional standards as a key means of enhancing teacher quality (e.g. OECD, 2005; Scheerens, 2010), and indeed, serve to define quality. The development and use of teacher professional standards has become so normalised that Bourke, Ryan and Lidstone (2013), writing from an Australian perspective, 
suggest that "no debate actually exists about the usefulness of standards; their implementation has become taken for granted" (p. 409).

Professional standards serve not only to enhance quality, but also as a tool for measuring or evaluating quality, something that is increasingly seen as a key component of most teacher education reform policies. In their review of empirical research on 'teacher evaluation and school improvement', Hallinger et al. (2014) claim that standards-based teacher evaluation, coupled with 'value-added' measurement of growth in student performance, are the hallmarks of what they term "new generation models of teacher evaluation" (p. 5). These new models reflect an era of increasing accountability, one which Hallinger et al. claim "has gradually shifted from holding schools accountable for policy compliance to accountability for learning outcomes" (2014, p. 6).

Much of the empirical literature reviewed by Hallinger et al. originates from the United States of America, and is reflective of a particular political and cultural context. Nonetheless, their conclusions are striking: they claim that "the "policy logic" driving teacher evaluation remains considerably stronger than empirical evidence of positive results" (p. 21). Despite a lack of empirical evidence to suggest a clear causal link, raising teacher quality through systematic evaluation of teachers against prescribed standards is a very popular and widespread policy solution.

While it must be acknowledged that professional standards vary in content, form and purpose, they generally outline key knowledge and skills required for teachers. However, Clarke \& Moore (2013) caution over the usefulness of standards that try to encompass everything a teacher should know. There is a risk that they will be ultimately rendered

so vague by the fundamental impossibility of taking account of the idiosyncratic and the contingent in teaching and learning as to result in their being reduced to mere statements of the obvious ... (p. 489).

Supporters of teacher professional standards highlight the capacity of standards to provide "a basis for deliberation and reflection" within learning communities and to provide a framework for teachers' career progression (Ingvarson, 1998, p. 129). Others claim that 
standards serve to uphold public trust in teaching and teachers, a necessary condition for any profession (Goepel, 2012).

It is apparent, then, that standards serve a number of functions, including accountability measures that contribute to the regulation of the profession. They also make explicit the knowledge and skills required by teachers, thereby providing a framework for initial teacher education curriculum and for graduate teacher professional development. Importantly, they serve to communicate publicly the essence of teaching within a particular national context. What they do not tell us is how the standards are enacted in practice, revealing a common policy-tension: "Policy is both text and action, words and deeds, it is what is enacted as well as what is intended" (Ball, 1994, p. 10). Such official statements of what it means to be a teacher have a particular authority attached to the words, and thus, serve to shape discourses of teaching, often in powerful ways.

Against this background we examine how cultural diversity and culturally diverse (CALD) ${ }^{1}$ students are positioned within teacher professional standards from some of the most culturally diverse nations and contexts in the world: England, Australia, New Zealand, Canada (British Columbia), The United States of America (California). ${ }^{2}$ We also examine how these standards address teacher knowledge and teacher practice for culturally diverse contexts. We want to be clear that what we present here is an analysis of policy texts - we do not purport to analyse the enactment of the policy documents. Not that the enactment of policy texts - in this case professional standards for teachers - is unimportant, rather that the essence of what we want to investigate is the 'official' policy message as represented in formal policy texts.

In what follows, we outline and justify the documents selected and then present our analysis before discussing our findings and drawing conclusions.

\section{Documents selected for analysis}

We have chosen to examine each of the particular sets of standards in the five nations listed above because there is long standing and significant cultural and linguistic diversity within

\footnotetext{
${ }^{1}$ We use the term CALD to refer to students of ethnic or racial minority who are first or second generation immigrants or who are Aboriginals.

${ }^{2}$ In the case of the USA and Canada, teacher professional standards are developed and implemented by particular state/provincial authorities.
} 
the populations of each of these national or state contexts. There is also a well-established need to prepare culturally responsive teachers. In the case of British Columbia, one of the most culturally diverse provinces in Canada, 27.6\% of the population in 2011 was foreign born with the two most common countries of birth being China (14.1\%) and India (12.0\%) (Government of Canada, n.d.). Of British Columbia's population, 27.3\% identified as 'visible minorities' from Chinese, South Asian and Filipino backgrounds and 5.4\% identified as Aboriginal (Government of Canada, n.d). California is a culturally and linguistically diverse state with $43.5 \%$ of its population speaking a language other than English at home (United States Census Bureau, n.d.). It has more hispanics than any other ethnic group, including white Americans, and significant numbers of American Indians and Asians (United States Census Bureau, 2013). In 2011, 27\% of California's population was foreign-born with the vast majority from Latin America, (53\%) and Asia (37\%) as well as Mexico, the Philippines and China (Johnson and Mejia, 2013). In the case of England, in 2013, 18.1\% of primary school pupils and $13.6 \%$ of secondary school pupils did not have English as their first language, with numbers over $76 \%$ and $69 \%$ respectively in some areas such as Tower Hamlets in London (NALDIC n.d.). Furthermore, ethnic minority and black minority ethnic students, who are not necessarily reflected in English as an Additional Language (EAL) figures, are approximately 24\% of the total student population in England (NALDIC, n.d.).

At the last Australian census in 2011, 15.7\% of the total populations was born in a non-main English speaking country (ABS, 2012). Apart from English there are over 200 different languages spoken in Australia with $18.2 \%$ of the population speaking a language other than English, at home (The Australia Community Profile, n.d). While the Indigenous population was only 3.0 of the total population in 2011 (ABS, 2013), there are approximately 160 different Aboriginal languages spoken (Department of Immigration and Border Protection, 2014b).

Where a country has more than one set of standards we looked at the standards document relating to initial licensing/registration, that is, the standards relevant to newly graduated teachers. We also acknowledge that our selection was limited to documents published in English. It is important to note that the five standards documents analysed have been developed at different times, in different contexts, and are authored and authorised by a range of different bodies/organisations ranging from teaching councils to government departments. 
They are, therefore, quite different in nature. Thus, we are not interested in comparing standards or national/state contexts. Below we provide a brief overview of each document.

\section{Australia}

The 'Australian Professional Standards for Teachers' is specifically aimed at graduate teachers at various stages of their careers, is published by the Australian Institute for Teaching and School Leadership (2011), an organisation set up and funded by the Australian Government. Seven professional standards are grouped under 3 domains of teaching: Professional Knowledge; Professional Practice; Professional Engagement, with each standard listing a number of specific areas of focus, and describing key competences for each. This runs to thirty-seven separate competence statements across the seven aspects. The document contains a brief overview of the development and organisation of the standards as well as information about their intended use.

\section{Canada - British Columbia.}

The $4^{\text {th }}$ edition of the 'Standards for the Education, Competence and Professional Conduct of Educators in British Columbia' is published by the British Columbia Ministry of Education (2012). It consists of a two page overview that outlines the 'purpose and meaning of the standards in practice', leaning heavily on a rationale that sees the standards as a means of ensuring teachers' commitment to meeting the needs of the public, and contributing to public good. The final page lists eight statements about 'educators', with a paragraph under each, outlining what might reasonably be expected of teachers. These standards deliberately lack detail and it is made clear by the authors that they are intended as "statements of principle upon which detail can be built" (p.2).

\section{The United States of America - California}

The 'Californian Standards for the Teaching Profession' were published by the Commission on Teacher Credentialing (2009), an agency in the Executive Branch of California State Government responsible for teacher professional standards. The document lists individuals involved in the development process and provides four pages of background information covering the history, development, context and philosophy of the standards. It then goes on to list six separate aspects, each providing a range of specific competences, accompanied by bullet-pointed lists of illustrations and examples. This runs to a total of thirty-seven competences, each with between three and eight illustrations of practice. 


\section{England}

The revised English 'Teachers' Standards' were published by the Department for Education (2013). The document contains four and a half pages of introductory information which outlines the statutory nature of the standards and describes the structure and intended use of the document. There then follows a list of eight aspects appearing under 'Part One: Teaching', each aspect containing a number of bullet-pointed competences (thirty-five in total). 'Part Two: Personal and Professional Conduct' lists three statements which "define the behaviours and attitudes which set the required standards for conduct" (p. 10).

\section{New Zealand}

The 'Graduating Teacher Standards: Aotearoa New Zealand' are published by the New Zealand Teachers' Council (2007). This document is contained on one page, listing seven standards under three headings: Knowledge; Practice; and Values and Relationships. Each standard lists between three and five associated competences. The document gives no information about its genesis, development or intended use.

\section{The Framework for Analysis}

Drawing on literature about culturally responsive pedagogy, and critical discourse analysis, we have devised a framework for the analysis of the five sets of professional standards. The framework was intended to facilitate our understanding of how CALD students are named and acknowledged, and how particular teacher knowledge about CALD students and culturally responsive pedagogies is made explicit.

First, the principles of critical discourse analysis (CDA), and in particular, on Fairclough's notion of "discourse as a moment of social practices" (2001, p. 122) underpin our interrogation of the standards. This theoretical position acknowledges that what is represented in the documents is part of a broader discourse that works to produce the subject rather than simply reflect it. It is also important to consider Ball's (2006) position that "Only certain influences and agendas are recognised as legitimate, only certain voices are heard at any point in time within the commonsense of policy" (p. 45). This suggests that the 'products' of official policy are views that have been legitimised by those in positions of influence and power. Therefore, our analysis is limited to the official, legitimised discourses of the national and state contexts under scrutiny. What is being analysed in this study is the "discursive 
nature of reality" (MacLure, 2003, p. 6) as expressed through teacher professional standards. We have sought to identify what is being said about aspects of cultural and linguistic diversity, what language is being used to shape the potential interpretation of what is said, and importantly, what is not said, omitted, silenced or only implied.

Second, literature about culturally responsive pedagogy has also informed our framework for analysis. Much of the literature focuses on teacher knowledge, and specifically, two interrelated areas of teacher knowledge; 1) what teachers need to know about CALD students, 2) what they need to know how to do (eg. Gay, 2010; Hayes \& Juarez, 2012; Sleeter \& Cornbleth, 2011; Santoro, 2009). Knowing students is complex, and possibly the most important and fundamental element of teaching. It is pivotal to developing good studentteacher relationships, designing meaningful and relevant curriculum, using effective assessment strategies and practices. It is, in fact, central to everything a teacher does. In the case of CALD students, teachers need to understand their students on a number of levels. On the most fundamental level, teachers need to acknowledge the diverse cultures and languages that are present in student populations. However, simply knowing that students do not all share the same cultural and linguistic backgrounds is not sufficient. They also need to understand the nature of their students' cultural and linguistic heritage, that is, their cultural knowledge, traditions, values and practices. Only by understanding and valuing the cultural knowledge students bring to their learning can teachers understand what school practices and curricula are culturally relevant to CALD students and only then can they build on that knowledge in productive and positive ways. Goodwin (2010, p.25) suggests that to know students is to understand the "informal, cultural, or personal curricula that children embody the curriculum of home, the curriculum of community/ies, the curriculum of lived experiences".

One of the authors has argued elsewhere that in order to understand CALD students' cultures, teachers must also know themselves as encultured. This means knowing themselves as having an ethnicity, a set of cultural beliefs and values that shapes how they see and interact with students, what they expect of students, what they actually do in their classrooms and what they 'know' to be valuable and correct about particular schooling, teaching and teaching practices (Santoro, 2012; Santoro, 2015).

However, it is not enough for teachers to simply know, for example, that CALD students are 
bi-cultural, may be bi-lingual and bring to their learning a range of cultural expectations about schooling, and a range of cultural knowledges. Culturally responsive teachers need to have a repertoire of effective strategies to use in practice with CALD students (Sleeter and Cornbleth 2011; Griner and Stewart 2013; Harry and Klingner 2014) For example, they need to know how to build on students' existing cultural knowledge in order to scaffold their learning and to make links with sanctioned curriculum. They need to know how to use students' first language in the classroom to facilitae and enable second language learning, and in recognition that assessment are often culturally biased, they need to know how to design culturally sensitive assessments

Informed by the literature discussed above, the series of questions we have devised to interrogate the 5 sets of standards are grouped under two broad and related categories: 1) Knowledge about CALD Students and; 2) Knowledge About Culturally Responsive Practice. In other words, the questions focus on what teachers need to know about students and what they need to know how to $d o$.

\section{Knowledge about culturally and linguistically diverse students}

- Are CALD students named and identified in the standards?

- Is the need to know students' cultures made explicit?

- Is the need for teachers to acknowledge how their own ethnicity/culture shapes their practice, made explicit?

- Is there an explicit expectation that teachers respect cultural and linguistic diversity?

\section{Knowledge about culturally responsive practice}

- Are specific culturally responsive teaching strategies made explicit?

- Are culturally responsive assessment strategies made explicit?

- Are teaching strategies to foster respect for cultural and linguistic diversity in all students, made explicit?

The five standards documents were analysed individually using each of the above questions. In what follows we present our analysis for each question in the form of a narrative, supported by an analysis grid (see Appendix 1). Where there is no evidence of a particular attribute, we have shaded the relevant areas of the grid in order to highlight omissions and 
silences.

\section{The Analysis}

Are CALD students named and identified in the standards?

Each of the five sets of standards emphasise the need for education that addresses the needs of "all students" without necessarily identifying and naming CALD students, or, indeed, naming and identifying specific groups of CALD students. Four sets of standards acknowledge the diversity of the student body in general, with phrases such as "students with varying backgrounds", "an increasingly diverse student body", (California), "pupils of all backgrounds" (England) and "classroom diversity" (British Columbia). In its preamble, the Californian standards mention "the varied socio-cultural, racial, religious, ethnic, linguistic, and economic backgrounds" (p. 2) of all students. The Australian standards mention cultural diversity alongside other forms of diversity, making reference to "students with diverse linguistic, cultural, religious and socioeconomic backgrounds" (p. 1). The New Zealand standards refer to a "multicultural" and "bicultural" Aotearoa New Zealand (p. 1).

Only three of the five sets of standards name specific groups of culturally diverse students: "Aboriginal and Torres Strait Islander students" in Australia (p. 1); "all Aboriginal peoples, especially First Nations, Inuit and Métis" in British Columbia (p. 2); and Māori in New Zealand. In none of the documents is there specific reference to first or second generation immigrant groups or to Black and Minority Ethnic (BME) students.

Is the need to know students' cultures made explicit?

All, except the English standards, make reference to varying degrees, of the need for teachers' to know CALD students' cultural backgrounds. The New Zealand standards refer to the need for teachers to have knowledge of Maori culture and language. With a similar focus on Aboriginal students, the Australian standards require teachers to understand the "impact of culture, cultural identity and linguistic background on the education of students from Aboriginal and Torres Strait Islander backgrounds", to have a broad understanding of "Aboriginal and Torres Strait Islander histories, cultures and languages" (Australian Standards, p. 1). Australian teachers are also expected to understand their students' "diverse 
linguistic, cultural and religious backgrounds" (p.4). However, there is no mention of which specific groups need to be understood. The Californian standards suggest teachers "develop an understanding of families' racial, cultural, linguistic, and socioeconomic backgrounds" (p. 16).

Is the need for teachers to acknowledge how their own ethnicity/culture shapes their practice, made explicit?

None of the five sets of standards make explicit the need for teachers to acknowledge how their own ethnicity and culture shapes their practice. The New Zealand document, however, suggests that teachers understand the "complex influences that personal, social, and cultural factors may have on teachers and learners" (p. 1). 'Cultural Factors' is a very broad category, and taken alongside the conflation of teachers and learners, works to dilute the importance of the message about the need for teachers to understand themselves as encultured and how their positioning shapes their practice in CALD classrooms. Similarly, the Californian standards also hint at the importance of teachers' own backgrounds when they acknowledge the value of teachers' diverse backgrounds and perspectives (p. 3). There is no mention whatsoever, in the remaining three documents, of the need to acknowledge teachers' ethnic and cultural identities, suggesting by omission, that these identities are not of central importance to the practice of teaching.

Is there an explicit expectation that teachers respect cultural and linguistic diversity?

All sets of standards make it clear that teachers are expected to demonstrate respect for students in general. In regards to CALD students, New Zealand teachers are expected to demonstrate respect for Maori language and Maori language speakers (p. 1), Australian teachers are expected to "respect Aboriginal and Torres Strait islander people", and teachers in British Columbia are expected to "respect the diversity in their classrooms, school and communities" (p. 4). In England there is an expectation that teachers, through their behaviour within, and outside schools, will not undermine "fundamental British values, including democracy, the rule of law, individual liberty and mutual respect, and tolerance of those with different faiths and beliefs" (p.14). There has been considerable discussion in the media, and between education academics as to what constitutes the undermining of 'fundamental British values' and how teachers would demonstrate they have achieved this standard (E.g. Maylor, 
2014; Lander 2014). Given that this statement about British Values has been taken from the 'Prevent Strategy' (HM Government, 2011) which is part of the UK's counter-terrorism strategy aiming to identity and respond to risks of "Al Qa'ida inspired terrorism" (p.1) this particular standard might be seen as fostering suspicion of, and fear of difference, rather than respect, especially in regard to Muslims.

Are specific culturally responsive teaching strategies made explicit?

All of the standards documents offer advice rather than specific teaching strategies. Australian teachers are required to have in their repertoire of skills, "teaching strategies that are responsive to the learning strengths and needs of students from diverse linguistic, cultural, religious and socioeconomic backgrounds" (p. 8). Californian teachers are expected to "connect classroom learning to students' life experiences and cultural backgrounds" (p. 5). They are also expected to "organize subject matter to reveal and value different cultural perspectives" (p. 10). Two of the five sets of standards mention the need to take appropriate account of English as an Additional Language (EAL) learners. In the Californian standards, there is a focus on 'English language learners', learners with 'limited English language proficiency' and 'second language learners' with teachers being expected to monitor their learning, support their learning, facilitate their English language acquisition and to use these students' assessments to inform teaching practice. However, often these learners are grouped with 'special needs' learners. Similarly, New Zealand teachers are expected to be able to support 'English as an Additional Language (EAL) learners to succeed in the curriculum', as well as 'use te reo Ma-ori me nga- tikanga-aiwi appropriately in their practice'. The English standards suggest that teachers should "have a clear understanding of the needs of all pupils, including... those with English as an additional language" (p. 12). The British Columbian standards make no mention of practice specifically in relation to CALD students.

Are culturally responsive assessment strategies made explicit?

None of the standards documents made any specific mention of strategies to make assessment culturally relevant, nor do they acknowledge the need to do so.

Are teaching strategies to foster respect for cultural and linguistic diversity in students in general, made explicit? 
It is well accepted that education has a significant role to play in developing all students as culturally aware citizens who respect, value and understand cultural and linguistic difference in the communities in which they live. Teachers can foster these attributes in students by including different cultural perspectives in the curriculum, by ensuring the success of CALD students through relevant and sensitive pedagogy and through anti-racist education. No standards documents provide specific strategies. Two sets acknowledge the importance of fostering respect in students for culturally diversity. The Australian standards make mention of Indigenous and non-Indigenous relations, with teachers being expected to "Promote reconciliation between Indigenous and non-Indigenous Australians" (p. 11). Californian teachers should "help all students accept and respect diversity in terms of cultural, religious, linguistic, and economic backgrounds; learning differences and ability; gender and gender identity; family structure and sexual orientation; and other aspects of humankind" (p. 7).

In what follows we discuss the analysis in terms of prominent discourses and major omissions/gaps in the documents.

\section{Discussion}

All of the documents, to varying degrees, recognise that teachers need to respond to student diversity. However, the extent to which they acknowledge, value and make explicit, cultural and linguistic diversity, and pedagogies for CALD contexts, varies. There are three main sets of silences and omissions in the documents that we wish to highlight in this discussion.

First, in general, a discourse of inclusivity characterises the standards. Terms such as 'all learners', 'all students' or 'diverse learners' are to be found in all the professional standards, rather than the naming and identification of specific ethnic or racial groups of CALD students. We have also noted that others limit their acknowledgement of CALD students to 'English language learners' or 'English as an additional/second language learners', thereby conflating CALD students with those whose lack of English language competence positions them as needing particular pedagogical interventions. Others categorise 'special education' and 'special needs students' with students for whom English is an additional/second language. While we recognise the importance of acknowledging the challenges that face learners for whom English is a second or additional language, not all CALD students are necessarily second language learners, and neither do they need the same interventions as 
those students with learning disabilities. Such a focus on second language acquisition reduces cultural and linguistic diversity to linguistic diversity. Furthermore, it is a factor that needs only to be taken into account temporarily - until learners acquire English language competence. This discourse constructs CALD students as deficit, in need of remediation and 'normalising', in relation to dominant culture and language.

The analysis also reveals interesting issues about the ways in which politically pertinent concerns about specific groups of culturally diverse learners enter into the standards discourse, sometimes at the expense of recognising other culturally diverse groups. While we found silences in regard to the naming of particular groups of CALD students, the professional standards for national and state contexts that have Aboriginal populations such as New Zealand Aotearoa, Australia and British Columbia, made specific mention of those groups (although we note the California standards did not mention any First Nations groups). Such acknowledgment is extremely important and we do not wish to downplay its significance. However, CALD students are also students who are first and second generation immigrants or students whose ethnic or racial identity positions them outside the dominant cultural group such as black and minority ethnic students. This raises questions about why, apart from Aboriginal students, are some CALD groups not named. We suggest it raises questions about the inherently political nature of professional standards as being reflective of wider social policy priorities within individual nation states, thus illustrating the power of the standards documents to 'produce the subject' rather than simply reflect it.

Second, our analysis revealed significant silences and omissions in regards to teachers' own ethnic and racial positioning and the need to know how this shapes their practice. Knowing the 'ethnic self' and 'cultural self' is inextricably connected to understanding the cultural and ethnic 'other' and is crucial to developing culturally responsive pedagogies and effective classroom practice (Santoro, 2009). Applebaum, commenting on the connection in general, between understanding self and others, says;

When it is assumed that teachers can act as if they bring nothing into the classroom, teachers do not have to examine how their own identities and the frameworks within which they are constituted influence how they understand who their students are and what can be expected of them (2009, p. 383). 
However, those who are members of the majority cultural group face particualr challenges. They are often blind to the dominant socio-cultural discourses they operate within, and take up. Particular educational practices are simply assumed to be 'normal' and 'natural' rather than a product of, and a construction of, the dominant culture of which they are a member.

Third, our analysis has revealed omissions in regards to knowledge about specific strategies for culturally responsive teaching. No standards documents mention the need for teachers to have knowledge of particular and specific strategies. While this is perhaps reflective of the nature and perceived purpose of the standards, it does nonetheless serve to underplay the importance of culturally responsive pedagogy.

\section{Concluding Remarks}

We began this article by drawing on the globally accepted premise that teacher quality can be enhanced through professional standards. As Sahlberg (2011, p. 177) asserts, there is "a widely accepted - and generally unquestioned — belief among policymakers and education reformers ... that setting clear and sufficiently high performance standards [...] will necessarily improve the quality of desired outcomes". Given the increasing importance that has accrued to professional standards as indicators and drivers of quality practice, we were concerned, in particular, with how CALD students are positioned within teacher professional standards, and how the standards make explicit teacher knowledge and teacher practice for culturally diverse contexts.

Our analysis reveals that in general, the teacher professional standards we analysed do not acknowledge, let alone make explicit, the complex and specific knowledge and skills needed for culturally responsive teaching. The value laden statements about equity and access that generally characterise them do little to acknowledge the complexities inherent in the identities of culturally diverse learners, and neither do they stipulate what it is that must be known or how teachers should come to know it. We acknowledge that our analysis was restricted to a relatively small sample of standards documents. However, those that we chose were from some of the most culturally diverse nations/states in the world. It is therefore reasonable to expect that such nations/states might be more advanced in their approaches to supporting the development of culturally responsive teachers than others might be. 
We do recognise however, that different standards are written in different ways by different groups of professionals and are intended for slightly different purposes. This raises questions about whether it is possible, or even desirable, for professional standards to adequately account for the complex professional knowledge required by teachers, and the extent to which standards might reasonably be expected to provide statements about particular pedagogical approaches that teachers might adopt. Some scholars such as Clarke \& Moore (2013) caution over the usefulness of standards that try to encompass everything a teacher should know. They suggest there is a risk that professional standards will be ultimately rendered

so vague by the fundamental impossibility of taking account of the idiosyncratic and the contingent in teaching and learning as to result in their being reduced to mere statements of the obvious ... (p. 489).

But nonetheless, even taking into account the different and conflicting ways in which professional standards are conceptualised and critiqued by educational researchers, teachers and teacher educators, professional standards still serve to 'produce the subject', as Fairclough (2001) would argue, by informing and shaping the discourse of teaching within individual national contexts. If we are to rely on professional standards to support and prioritise aspects of teacher quality, then in the case of culturally responsive teachers and culturally responsive teaching practice, the standards appear to be a long way from providing the kind of steer necessary to make serious inroads into enhancing teacher quality in this regard. Thus, it seems reasonable to suggest that CALD learners should be positioned much more prominently in teacher standards and the complex knowledge about learners and about practice for CALD learners that is required by culturally responsive teachers, should feature in standards documents.

We acknowledge that teacher education programmes, at both initial and post-qualification stages, must take into account national guidance or direction framed through professional standards. In many national and state contexts, teacher registration is dependent on teacher education institutions demonstrating their courses facilitate the development of graduate attributes and knowledge in keeping with the professional standards. However, it is important for teacher educators to recognise the gaps and omissions in teacher professional 
standards, how they position CALD students and pedagogies for CALD classrooms. It is clear that teacher education must not rely alone on teacher professional standards to inform teacher education for the preparation of culturally responsive practitioners.

Finally, our analysis of the standards has raised a number of questions around why particular CALD groups are privileged over others in the standards, why there is generally a silence around the naming and identification of ethnic and racial groups, why the discourses of inclusivity that characterise the standards work at the same time to exclude, conflate and homogenise specific groups of CALD students. For us, these questions highlight the social discourses in which teacher professional standards are embedded and the inherently political nature of professional standards. However, the answers to these questions, while beyond the scope of this article, are nonetheless worthy of further consideration and research.

\section{References}

Applebaum, B. (2009). “Is Teaching for Social Justice a 'Liberal Bias'?” Teachers College Record, 111 (2), 376-408.

ABS (Australian Bureau of Statistics) (2013). Estimates of Aboriginal and Torres Strait Islander Australians, June 2011 (ABS Cat no. 3238.0.55.001), Canberra: ABS. http://www.abs.gov.au/ausstats/abs@.nsf/latestProducts/3238.0.55.001Media\%20Release1Ju ne\%202011(Accessed 1/11/2014).

ABS (Australian Bureau of Statistics) (2012). Cultural diversity in Australia - Reflecting a Nation: Stories from the 2011 Census, 2012-2013 (ABS Cat. no. 2071.0), Commonwealth of Australia: Canberra.

Australian Department of Immigration and Border Protection (2014a). Australian Migration Trends 2012-13, Commonwealth of Australia: Canberra.

Australian Department of Immigration and Border Protection (2014b). The People of Australia. Statistics from the 2011 Census, Commonwealth of Australia: Canberra. 
Australian Institute for Teaching and School Leadership (2011). National Professional Standards for Teachers, http://www.aitsl.edu.au/verve/_resources/AITSL_National_ Professional_Standards_for_Teachers.pdf

Ball, S. (1994). Education reform: A critical and post-structural approach, Buckingham: Open University Press.

Ball, S. (2006). What is policy? Texts, trajectories and toolboxes. In Education policy and social class: The selected works of Stephen J. Ball, Routledge: Abingdon.

Bourke, T., Ryan, M.E. \& Lidstone, J. (2013). Reflexive professionalism: reclaiming the voice of authority in shaping discourses of education policy. Asia-Pacific Journal of Teacher Education, 41(4), 398-413.

British Columbia Ministry of Education (2012). Standards for the Education, Competence an Professional Conduct of Educators in British Columbia, Vancouver: Ministry of Education Teacher Regulation.

Clarke, M. \& Moore, A. (2013). Professional standards, teacher identities and an ethics of singularity. Cambridge Journal of Education, 43(4), 487-500.

Commission on Teacher Credentialing (2009). California Standards for the Teaching Profession (CSTP). State of California.

Department of Education (2013). Teachers' Standards. Guidance for School Leaders, School Staff and Governing Bodies.

https://www.gov.uk/government/uploads/system/uploads/attachment_data/file/301107/Teache rs__Standards.pdf(accessed November 1, 2014).

Dustmann, C., Frattini, T. and Lanzara, G. (2011). "Educational Achievement of Second Generation Immigrants: An International Comparison ” Norface Discussion Paper No. 201125. 
Epstein, T. \& Gist, C. (2013). Teaching racial literacy in secondary humanities classrooms: challenging adolescents' of color concepts of race and racism, Race Ethnicity and Education, DOI: $10.1080 / 13613324.2013 .792800$

Fairclough, N. (2001). Critical discourse analysis as a method in social scientific research. In R. Wodak and M. Meyer (Eds.), Methods of critical discourse analysis, (pp. 121-138). London: Sage.

Gay, G. (2010). Culturally Responsive Teaching :Theory, Research and Practice, New York: Teachers College Press.

Goepel, J. (2012). Upholding public trust: An examination of teacher professionalism and the use of Teachers' Standards in England. Teacher Development, 16(4), 489-505.

Gonzales, N. E., L. C. Moll, and C. Amanti (2005). Funds of Knowledge: Theorizing Practices in Households, Communities and Classrooms, New York: Taylor and Francis.

Goodwin, A.L. (2010). Globalization and the preparation of quality teachers: rethinking knowledge domains for teaching, Teaching Education, 21(1), 19-32.

Government of Canada (n.d). Statistics Canada. NHS Focus on Geography Series - British Columbia. http://www12.statcan.gc.ca/nhs-enm/2011/as-sa/fogsspg/Pages/FOG.cfm?lang=E\&level=2\&GeoCode=59\#tabs1_2 (accessed June 2, 2014).

Government of Ireland (2012). Profile 6. Migration and Diversity, Central Statistics Office: Stationery Office, Dublin, Ireland. Available from http://www.cso.ie/en/media/csoie/census/documents/census2011profile6/Profile,6,Migration, and,Diversity,entire,doc.pdf

Griner, A.\& Stewart, M. (2013). Addressing the Achievement Gap and Disproportionality Through the Use of Culturally Responsive Teaching Practices. Urban Education, 48 (4), 585621. 
Hallinger, P., Heck, R.H. \& Murphy, J. (2014). Teacher evaluation and school improvement: An analysis of the evidence. Educational Assessment, Evaluation and accountability, 26(1), $5-28$.

Harry, B. \& Klingner, J. (2014). Why are so many minority students in special education?: understanding race and disability in schools, New York: Teachers' College, Columbia University.

Hayes, C., Juarez, B. (2012). There Is No Culturally Responsive Teaching Spoken Here: A Critical Race Perspective. Democracy and Education, 20 (1), Article 1.

HM Government (2011). Prevent Strategy, UK: British Parliament www.homeoffice.co.uk (accessed November 1, 2014).

Ingvarson, L. (1998). Professional development as the pursuit of professional standards: The standards-based professional development system. Teaching and Teacher Education, 14(1), 127-140.

Johnson, H. and Mejia, M.C. (2013). Just the Facts. Immigrants in California, Public Policy Institute of California. http://www.ppic.org/main/publication_show.asp?i=258 (accessed June 2, 2014).

Lander, V. (2014). Initial Teacher Education: the Practice of Whiteness. In R. Race, \& V. Lander, V. (Eds) Advancing Race and Ethnicity in Education, (pp. 93-110).Palgrave MacMillan Basingstoke, UK..

MacLure, M. (2003). Discourse in educational and social research, Buckingham: Open University Press.

Maylor, U. (2014, June 12). Promoting British values opens up a can of worms for teachers. The Guardian, Retrieved from http://www.theguardian.com/teacher-network/teacherblog/2014/jun/12/promoting-british-values-opens-up-a-can-of-worms-for-teachers October $30,2014$. 
NALDIC (National Association for Language Development In the Curriculum) (n.d.). EAL and Ethnicity Nationally and by Local Schools January 2013,

http://www.naldic.org.uk/research-and-information/eal-statistics/eal-pupils (Accessed on 2 June 2014).

OECD (2005). Teachers Matter, Paris: OECD.

OECD (2013). Country statistical profile: Iceland, Country statistical profiles: Key tables from OECD, doi: 10.1787/csp-isl-table-2013-2-en

OECD (2011). Pisa in Focus,

http://www.oecd.org/pisa/pisaproducts/pisainfocus/49264831.pdf accessed October 2014

Sahlberg, P. (2011). The fourth way of Finland. Journal of Educational Change, 12(2), 173184.

Santoro, N. (2009). Teaching in culturally diverse contexts: What knowledge about 'self' and 'others' do teachers need? Journal of Education for Teaching, 35(1), 33-45.

Santoro, N. (2013). The Making of Teachers for the Twenty-first Century: Australian Professional Standards and the Preparation of Culturally Responsive Teachers. In Xudong, Z. \& and Zeichner, K. (eds). Preparing Teachers for the Twenty-first Century. (pp. 309-321) Springer.

Santoro, N. \& Forghani-Arani (2015) Interrogating practice in culturally diverse classrooms: what can an analysis of student resistance and teacher response reveal?, European Journal of Teacher Education, DOI: 10.1080/02619768.2014.944158

Scheerens, J. (Ed.). (2010). Teachers' professional development: Europe in international comparison, European Union: Luxembourg. http://ec.europa.eu/education/schooleducation/doc/talis/report_en.pdf 
Schleicher, A. (2014). Equity, excellence and inclusiveness in education: Policy lessons from around the world, Paris: OECD.

Sleeter, C. E., Cornbleth, C. (Eds). (2011) Teaching with Vision: Culturally Responsive

Teaching in Standards-Based Classrooms, New York: Teachers College Press.

The Australia Community Profile (n.d). Australia. Language Spoken at Home, http://profile.id.com.au/australia/language?BMID=50\&WebID=10(Accessed 1/11/2014).

United States Census Bureau (2013). Newsroom. Asians Fastest-Growing Race or Ethnic Group in 2012, Census Bureau Reports,

https://www.census.gov/newsroom/releases/archives/population/cb13-112.html accessed June 2, 2014

United States Census Bureau (n.d). States and County Quick facts, California, http://quickfacts.census.gov/qfd/states/06000.html (accessed June 2, 2014).

\section{Appendix 1: Analysis Table}

\section{Knowledge About CALD Students}

Are CALD students named and identified?

\begin{tabular}{|c|c|c|c|c|c|}
\hline & Australia & $\begin{array}{l}\text { British } \\
\text { Columbia }\end{array}$ & England & $\begin{array}{c}\text { New } \\
\text { Zealand }\end{array}$ & California \\
\hline $\begin{array}{l}\text { General diversity of student population } \\
\text { acknowledged }\end{array}$ & $\mathrm{X}$ & $\mathrm{X}$ & $\mathrm{X}$ & $X$ & $\mathrm{X}$ \\
\hline $\begin{array}{l}\text { Cultural diversity of student population } \\
\text { acknowledged }\end{array}$ & $\mathrm{X}$ & $X$ & & $X$ & $X$ \\
\hline $\begin{array}{l}\text { Specific groups of CALD students named and } \\
\text { identified }\end{array}$ & $\mathrm{X}$ & $X$ & & $X$ & \\
\hline $\begin{array}{l}\text { First or second generation immigrant groups named } \\
\text { and identified }\end{array}$ & & & & & \\
\hline $\begin{array}{l}\text { Black and Minority Ethnic (BME) students named } \\
\text { and identified. }\end{array}$ & & & & & \\
\hline
\end{tabular}


Is the need to know students' cultures made explicit?

\begin{tabular}{|c|c|c|c|c|c|}
\hline Knowledge about culture in general & $\mathrm{X}$ & $\mathrm{X}$ & & $\mathrm{X}$ & $\mathrm{X}$ \\
\hline Knowledge about language & $\mathrm{X}$ & & $\mathrm{X}$ & $\mathrm{X}$ & $\mathrm{X}$ \\
\hline Knowledge about religion & $\mathrm{X}$ & & & $\mathrm{X}$ & $\mathrm{X}$ \\
\hline $\begin{array}{l}\text { Knowledge about cultural practices and values in } \\
\text { general }\end{array}$ & $\mathrm{X}$ & & & $\mathrm{X}$ & \\
\hline
\end{tabular}

Is the need for teachers to acknowledge how their own ethnicity/culture shapes their practice, made explicit?

\begin{tabular}{|l|l|l|l|l|l|}
\hline Teacher ethnicity in regards to practice & & & & \\
\hline Teacher culture in regards to practice & & & & $\mathrm{X}$ & \\
\hline Teacher culture in general & & & & & \\
\hline Teacher ethnicity in general & & & & & \\
\hline Teacher background in general & & & & & $\mathrm{X}$ \\
\hline
\end{tabular}

Is there an explicit expectation that teachers respect cultural and linguistic diversity?

\begin{tabular}{|l|c|c|c|c|c|}
\hline Respect for all students, in general & $\mathrm{X}$ & $\mathrm{X}$ & $\mathrm{X}$ & $\mathrm{X}$ & $\mathrm{X}$ \\
\hline Respect for CALD students & $\mathrm{X}$ & & & $\mathrm{X}$ & \\
\hline Respect for diversity in general & & $\mathrm{X}$ & & & \\
\hline
\end{tabular}

\section{$\underline{\text { Knowledge About Culturally Responsive Practice }}$}

Are specific culturally responsive teaching strategies made explicit?

\begin{tabular}{|c|c|c|c|}
\hline Specific strategies & & & \\
\hline $\begin{array}{l}\text { Pedagogical responsiveness to second language } \\
\text { learners }\end{array}$ & & $\mathrm{X}$ & $\mathrm{X}$ \\
\hline $\begin{array}{l}\text { Pedagogical responsiveness to CALD students in } \\
\text { general }\end{array}$ & $X$ & & $\mathrm{X}$ \\
\hline
\end{tabular}

Are culturally responsive assessment strategies made explicit?

\begin{tabular}{|l|l|l|l|l|l|}
\cline { 2 - 5 } \multicolumn{1}{l|}{} & Australia & $\begin{array}{c}\text { British } \\
\text { Columbia }\end{array}$ & England & $\begin{array}{c}\text { New } \\
\text { Zealand }\end{array}$ & California \\
\hline $\begin{array}{l}\text { Are culturally responsive assessment strategies } \\
\text { acknowledged? }\end{array}$ & & & & & \\
\hline $\begin{array}{l}\text { Are culturally responsive assessment strategies } \\
\text { made explicit? }\end{array}$ & & & & & \\
\hline
\end{tabular}

Are specific teaching strategies to foster respect in all students, made explicit? 


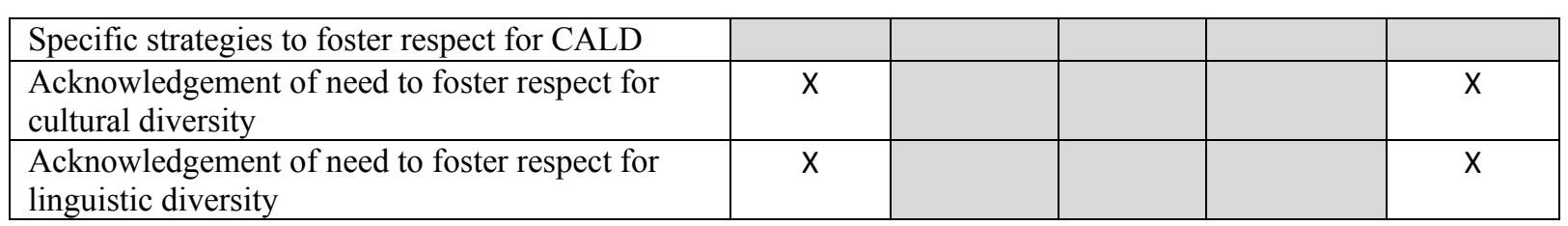

